\title{
Perspectivas e possibilidades de abordagem das mediações no trabalho investigativo: questões envolvendo o rural e o rádio
}

\author{
Graziela Bianchi \\ Doutora; Universidade Estadual de Ponta Grossa, Ponta Grossa, PR, Brasil \\ grazielabianchi@yahoo.com.br
}

\section{Resumo}

A cultura, situada no trabalho desenvolvido por Jesús MartínBarbero, ocupa um lugar destacado para se observar relações estabelecidas com distintos meios de comunicação. Considerando essa compreensão, busca-se avançar em discussões a respeito de como, a partir do olhar que é mobilizado desde a cultura, diferentes processos de mediação podem ser investigados. De modo mais detido, a apresentação de questões que envolvam a pesquisa com públicos em comunidades rurais em suas relações e construções de trajetórias com o meio radiofônico. Nesse sentido, a apresentação e reflexão dos processos envolvidos na investigação da perspectiva em que o rural se apresenta como uma mediação articuladora entre as demais mediações envolvidas em um processo comunicacional de natureza radiofônica.

\section{Palavras-chave}

Mediações. Rádio. Rural. Ouvintes. Cultura.

\section{Introdução}

A perspectiva teórico-metodológica trabalhada por Jesús Martín-Barbero (1987, 1988, 1998, 1999, 2002, 2006) auxiliou, e segue sendo uma importante referência para investigações desenvolvidas em diferentes âmbitos, sob distintas condições, propiciando aos pesquisadores interessados nas mais amplas e plurais abordagens, um caminho a ser trilhado. Suas noções e concepções trazidas para pensar, em especial, os processos 
comunicacionais, observados e refletidos a partir de um viés em que a cultura ocupa papel destacado, trouxeram um importante sentido para uma pluralidade de estudos desenvolvidos especialmente a partir dos anos 1990, de maneira mais evidente, em investigações empreendidas em regiões e países da América Latina.

Essa constatação se articula ao fato de Martín-Barbero ter avançado em suas reflexões estando situado nesse espaço geográfico, mais especificamente, a Colômbia. Mas esta não é a única "explicação" que ajuda a fundamentar o avanço de suas propostas teóricometodológicas. Suas construções, baseadas em um olhar que parte da cultura para entender os diferentes processos comunicacionais (não só eles, mas pensando nestes como um foco destacado de interesse) teve o desdobramento que tornou amplamente conhecida e reconhecida a perspectiva que propõe o entendimento de processos culturais, e incluso nestes os comunicacionais, a partir de construções que compreendem as mediações como condições privilegiadas para se compreender uma série de fenômenos, a partir de um olhar cultural. Pode-se dizer, então, que a América Latina encontra particularidades e relações bastante evidentes para que represente um lugar fértil para tais desenvolvimentos.

Nas últimas décadas, tais contribuições vêm se constituindo também como uma área de estudos com abordagens e condições teórico-metodológicas particulares e bastante efetivas. Pensar as mediações envolvidas nos processos, os comunicacionais, sobretudo, tem emanado importantes desafios, mas também representa uma série de ganhos em termos de possibilidades de avanços em cada direcionamento relacionado pelas pesquisas que aderem e fazem uso de suas abordagens.

No processo investigativo que servirá de referência para discutir o trabalho das mediações culturais, a partir da perspectiva articulada por Martín-Barbero, as articulações presentes nos processos de escuta radiofônica em ambientes rurais, considerando o rural exatamente como uma mediação articuladora. A pesquisa, desenvolvida entre 2001 e 2002, percebida agora especialmente a partir de seus processos metodológicos, com atenção especial dada às mediações, servirá como base para se refletir a respeito da atuação e mobilização de distintas mediações presentes nos processos de escuta radiofônica.

No desenvolvimento da investigação que dá origem a esse fragmento reflexivo, são apontadas e ressaltadas, em diferentes momentos, concepções compartilhadas com distintos autores, entre eles, Martín-Barbero. E dentro das elaborações por ele realizadas, e aqui compartilhadas e refletidas, faz-se referência direta à perspectiva utilizada em suas elaborações conceituais, geradas a partir de vivências concretas no trabalho investigativo, 
que direciona o olhar para os fenômenos investigados desde a cultura. Mais do que uma perspectiva com a qual essa reflexão também se alinha, é uma maneira fundamental para conseguir compreender fenômenos que se revelam no âmbito de pesquisa.

Assim, o presente trabalho, em sua estrutura descrita e articulação constituída, se propõe a avançar em algumas discussões e reflexões contidas e abarcadas pela interface entre os processos de comunicação e o rural, tendo o rádio como um elemento principal de interesse, a partir de interações e construções mobilizadas por seus ouvintes. Nesse sentido, o texto percorre algumas trilhas para compreender a participação do trabalho das mediações, tendo uma centralidade demarcada em torno do rural. São trazidas, então, no desenvolvimento do artigo, questões que discutem, no tópico 2, o processo operativo e de construção de sentidos a partir das mediações em ação evidenciadas e observadas na investigação de referência. Já no item 3 do texto, são observadas e consideradas as relações que se estabelecem entre os processos de produção, produto e recepção vinculadas ao radiofônico e ao rural e que estão implicadas nos processos comunicacionais arrolados pela investigação e trabalhados, refletidos por este artigo.

Tais abordagens são organizadas aqui e interessam na medida em que existem, nesse trabalho, algumas mediações que foram consideradas como fundamentais. É possível dizer que existem mediações que desempenham um papel relevante na conformação, no desenvolvimento e na manutenção de uma trajetória radiofônica, vistas e consideradas a partir da perspectiva do ouvinte. Também nesse contexto se articulam e desenvolvem mediações que são fundamentais para entender e perceber mecanismos de criação e manutenção de habitus (BOURDIEU, 2007) relacionados ao consumo e relacionamento com o rádio. E, vinculado a esses aspectos, o cenário onde se apresenta essa diversidade de configurações, que irá exercer papel determinante no consumo radiofônico dos ouvintes, que é o cotidiano.

Para se compreender de maneira mais efetiva o conceito de mediação, é importante expressar a maneira como o próprio Martín-Barbero não só concebe, mas trabalha de forma efetiva essa elaboração em seus processos de investigação:

Ao invés de iniciar a investigação da análise das lógicas de produção e recepção, e depois buscar suas relações de imbricação ou confrontação, nos propomos a partir de mediações, isto é, dos lugares dos quais as constrições que delimitam e eles moldam a materialidade social e a expressividade cultural da televisão. Por meio de hipóteses, que recolhem e dão forma a uma série de buscas convergentes, embora muitas não possuam televisão "objeto", três lugares de mediação são propostos: o 
cotidiano familiar, a temporalidade social e a competência cultural. (MARTÍN-BARBERO, 1998, p. 298, tradução nossa).

Aqui estão relacionados alguns dos elementos que figuram de certa maneira como balizadores para a compreensão de como as mediações operam. E, nesse sentido, revela-se a forma como esse conceito pode ser referido e trabalhado em um processo investigativo. Também no entendimento das mediações, fica claro o fato de que, para o autor, o conceito está em relação com outro elemento importante, que diz respeito ao cotidiano. A citação revela um cotidiano familiar, mas essa noção pode ser ampliada, relida ou mesmo confrontada com outras. Toda essa elaboração está, então, muito próxima de questões com as quais a investigação de referência tem deparado.

A perspectiva que percebe o cotidiano como um lugar para se observarem dimensões relacionadas ao consumo radiofônico não minimiza a importância de outros elementos que também se apresentam como mediações dentro desse processo. Essas mediações, tomadas como fundamentais no entendimento das operações relacionadas à escuta radiofônica, representam um trabalho de composição que precisa ser realizado para que se cheguem às elaborações de fundo midiático. São construções de natureza micro e macro, onde se olha o geral, mas também o particular, onde o processo que dá origem a tal multiplicidade é que expressa a riqueza. Nas palavras de Martín-Barbero (2002), é um movimento de articulação peculiar, que desloca o ponto de vista de concepções um tanto arraigadas para dar espaço a movimentos que percebem essas manifestações sob outra perspectiva:

A partir daí, da superação ativa do maniqueísmo aristocratizante ou populista, se coloca em evidência a necessidade de contar com algo como um "mapa noturno", que nos permita, ao mesmo tempo assumir a pluralidade na qual estão feitos estes usos e estabelecer articulações entre as operações de- retirada, rejeição, assimilação, refuncionalização, de redesenho-, as matrizes-, de classe, de território, de etnia, de religião, de sexo, de idade - os espaços - o habitat, a fábrica, o bairro, a prisão-, e os meios- micro como o gravador ou a fotografia, médio, como o disco ou o livro, macro como a imprensa, o rádio ou a TV. Mas sem esquecer que em qualquer caso será um mapa "noturno", esta informação remeterá sempre mais ao que se intui e à experiência do que ao que se vê. Uma boa imagem para cifrar o que para mim tem sido e ainda é a travessia pela comunicação a partir do popular. (MARTÍN-BARBERO, 2002, p. 135, tradução nossa).

Estão postas, então, as questões fundamentais para o entendimento das mediações como possibilidades de compreensão dos processos que relacionam a escuta radiofônica. 
São perspectivas que precisam ser vistas de maneira articulada e relacionada na composição de elementos que constituem o problema/objeto da investigação.

0 presente artigo se desenvolve tendo como direcionamento fundamental o trabalho das medições sendo operadas a partir da investigação que relaciona questões da escuta radiofônica em ambientes rurais. No avanço do trabalho, também há a presença de articulações entre produção, produto e recepção com a participação das mediações de forma ativa no desenvolvimento investigativo.

\section{Mediações em operação}

A compreensão dos sentidos gerados no processo comunicacional, articulando a produção midiática, seus produtos veiculados e a recepção dessa oferta representa um desafio na área de estudos em comunicação. 0 trabalho aqui exposto segue nessa direção, buscando relacionar e compreender mecanismos, apropriações, conflitos, consonâncias e dissonâncias presentes nesse processo onde pode ser evidenciada uma multiplicidade de nuances. Algumas delas se farão aqui presentes. Destaca-se, no entanto, a presença das mediações como uma articulação central na conformação vivenciada pelo processo de investigação.

0 percurso de pesquisa que relaciona as configurações e relações existentes entre o rural vivenciado e o rural midiatizado é o principal eixo condutor da pesquisa referenciada ${ }^{1}$. A partir dessa questão central, presente no processo de condução da investigação, busca-se compreender o relacionamento entre o rural vivido e midiatizado no que se refere aos sentidos gerados na relação existente entre as duas instâncias. Buscou-se identificar e investigar de que maneira se dão as apropriações, conflitos, consonâncias e dissonâncias na relação de uma instância com a outra. Nesse relacionamento, a necessidade de se compreender como se configura a presença do rural no midiático e do midiático no rural. Assim, revelou-se a necessidade de se estabelecer relações que acontecem entre os processos midiáticos e os processos socioculturais.

É importante evidenciar a maneira como se compreende o relacionamento entre o rural vivido e midiatizado. Parte-se do pressuposto de que essas duas configurações possuem pontos de convergência e divergência. Nenhum dos dois aspectos apresenta uma

\footnotetext{
10 trabalho diz respeito à dissertação desenvolvida pela autora, e defendida em 2003, com o título Rural vivido e midiatizado relações simbólicas e sentidos produzidos a partir da escuta dos programas radiofônicos Hora do Chimarrão e Brasil de Norte a Sul por ouvintes das comunidades rurais Linha Batistela, Povoado Coan e Linha Bigolin (BIANCHI, 2003).
} 
forma 'pura', cada um deles exerce influência e tem aspectos da constituição do outro. 0 vivido participa da existência do midiatizado e o midiatizado guarda em si aspectos que compõem o vivido.

Entretanto, cada um deles se relaciona a uma existência específica, com lógicas específicas. No midiático, a presença de especificidades que participam em sua constituição, como suas estratégias, temporalidades, linguagens. Da mesma maneira, o vivido também é detentor de lógicas específicas, como práticas cotidianas, mediações que o constituem, relações que se estabelecem com vistas aos mais diferentes objetivos. Busca-se relacionar as duas instâncias, compreendendo de que maneira elas participam na construção de sentido do rural que vai ser veiculado por programas radiofônicos.

Os aspectos pesquisados, no que se refere à produção e aos produtos midiáticos em questão, dizem respeito às estratégias utilizadas para a vinculação do que se está considerando como sentido de rural midiatizado. Tais estratégias estão relacionadas ao conjunto de mecanismos que se fazem presentes na oferta midiática e que estão relacionados entre a construção de discursos, a utilização de aparatos técnicos, da inserção de música no contexto dos programas radiofônicos, dos recursos utilizados pelo apresentador, da presença de notícias, das diferentes inserções do ouvinte, entre outros. É importante destacar que tais aspectos são constituintes, considerando suas particularidades de articulação, de formas para melhor se compreender como se organizam os distintos elementos que compõem a conformação os processos radiofônicos nos quais interessa também avançar no entendimento relacionado à recepção em contexto rural. Para tanto, a seguir serão organizadas e descritas uma série de pontos de interesse em que as questões das mediações estão também diretamente implicadas. Nesse sentido, a presença de aspectos como os aparatos técnicos e suas funções nos programas radiofônicos em análise, assim como a participação da música, dos conteúdos noticiosos, da publicidade, da presença de comentários, incluindo também a presença do humor nas produções, assim como o do papel do apresentador dos programas analisados.

Na perspectiva do uso de aparatos técnicos, a observação se dá no sentido de verificar de que forma esses dispositivos se configuram no contexto dos programas radiofônicos pesquisados, qual seu papel, de que maneira são utilizados e com quais objetivos. Tais dispositivos são representados especialmente por recursos sonoros gravados com o objetivo da produção de efeitos nos programas. Para a avaliação destes aspectos, buscou-se, além da escuta sistemática das produções radiofônicas Hora do 
Chimarrão e Brasil de Norte a Sul (veiculados, respectivamente, no período matutino nas emissoras Difusão AM e Erechim AM, ambas situadas no município de Erechim, região norte do Rio Grande do Sul), a investigação sobre a consideração dos graus de importância dos fatores elencados dada pelos apresentadores-produtores dos programas. Da mesma maneira, observou-se o papel da música como dispositivo constituinte para o sentido que a mídia rádio vincula ao rural, os vínculos que cria, especialmente a partir da utilização de músicas sertanejas, produzidas preferencialmente nas décadas de 1960 e 1970, e gauchescas. 0 papel dessas músicas para a criação do rural midiatizado é um aspecto que também é investigado (BIANCHI, 2003).

O sentido que se atribui ao rural, via música, passa não só pela instância da produção como também encontra consonância na recepção. Na relação do uso de tal dispositivo como produtor de sentido vinculado ao rural, a análise é executada de maneira a identificar quais os tipos de músicas que possuem maior incidência nos programas, os tempos e contextos em que são apresentadas, as vinculações que firmam com os comentários dos apresentadores, com as notícias presentes nos programas, no trabalho de construção de um ouvinte imaginado, por parte de apresentadores e produtores.

Considera-se então a música como sendo um dispositivo que possui vinculação com matrizes culturais que remetem os receptores a um sentido de ruralidade, expressos por temáticas relacionadas ao homem do campo, o sertanejo, o peão, o cotidiano no campo, no interior. Relaciona-se que sentidos são esses, o que significam na vida cotidiana dos ouvintes e de que maneira contribuem na composição do rural midiatizado. Que correspondência existe entre a midiatização do rural, a relação com o rural vivido e a audição de músicas preferencialmente dos gêneros sertanejo e gauchesco.

No que se relaciona à presença de notícias nos programas em análise, a observação de uma construção discursiva vinculada ao campo do jornalismo como um dispositivo também utilizado na construção do rural midiatizado. 0 espaço destinado às notícias opera de maneira legitimadora de um discurso que constrói o rural veiculado pelos programas em análise. 0 jornalismo figura como um 'atestado de veracidade' acerca do que se constrói discursivamente em relação ao rural. Relacionam-se essas construções a partir de um recurso tipicamente midiático como instaurador e/ou legitimador de sentido do rural. (BIANCHI, 2003, p. 16).

As informações divulgadas nos espaços noticiosos dos programas são vistas pelos receptores como essenciais não só na constituição dos programas, mas também se revelam 
como preponderantes no seu cotidiano. Busca-se relacionar o que significam essas informações para esses ouvintes, quais sentidos produzem não só na relação com as demais partes do programa, mas também no dia a dia desses indivíduos.

Relaciona-se também à importância que se atribui ao conteúdo informativo divulgado pelos programas, a relação desses aspectos como a temporalidade com que essa informação é consumida. 0 consumo verificado não se dá de maneira linear, sendo atravessado por diversas outras mediações cotidianas como o trabalho, a família e a escola. Entretanto, cabe salientar que perpassando essas e outras mediações existentes está o rural, figurando como a mediação que atravessa todas as demais.

O conteúdo informativo é diversificado e variadas também são suas apreensões, relações, aceitações e recusas. Percebe-se que, no que se refere à temática relacionada ao rural, o interesse exposto pelos ouvintes pesquisados é relevante, sendo sobreposta em quase todas as expressões à insatisfação com o pouco espaço destinado à informação rural. Observa-se, então, como essa questão é vista por parte da produção dos programas. Investigam-se os critérios de noticiabilidade utilizados e a posição assumida no que se refere às notícias relacionadas ao rural.

Para tanto, é necessária a compreensão da maneira como são concebidas as informações divulgadas, as fontes consultadas, a existência ou não de uma equipe de jornalismo, além da análise das notícias veiculadas, seu formato, os assuntos tratado e, sua contextualização. Nesse aspecto, recorre-se ao discurso jornalístico, analisando-se as marcas discursivas que de alguma maneira vinculam o sentido ao rural midiatizado.

A partir de uma outra lógica, há a importância de se observar o papel do espaço publicitário presente em diferentes configurações no decorrer dos programas. 0 comercial gravado, narrado pelo apresentador, os produtos anunciados e seus sentidos que também se vinculam ao rural. Dois estilos de publicidade apresentam-se como preponderantes (o comercial gravado pelo apresentador do programa ou outro profissional e o comercial narrado ao vivo). Relacionam-se, então, os sentidos presentes na sua constituição e o significado da escolha dessas duas formas de se fazer publicidade.

De certa maneira, os comerciais não exercem somente a função relacionada diretamente ao consumo na vida concreta, mas estão inclusos em uma lógica de consumo simbólico, além de figurarem, em algumas ocasiões, como estratégia de convencimento utilizada pelos apresentadores. Tal expressão é visível no caráter de humor empregado, na possibilidade de relações e atribuições de juízos de valor utilizadas no espaço comercial. É 
estabelecida a compreensão da forma como a parcela publicitária dos programas se revela na construção do rural midiatizado. Para tanto, relacionam-se os anunciantes presentes nos programas, o formato dado às publicidades, às vinculações existentes entre o espaço publicitário e o jornalístico, entre o espaço de intervenção dos apresentadores, com o espaço musical, tendo como horizonte o sentido relacionado ao rural midiatizado.

A presença de comentários, humor e a necessidade evidenciada pelos indivíduos que ocupam a posição de apresentadores dos programas de um permanente diálogo com os ouvintes, como se fossem instauradas relações face a face, é também um aspecto investigado. No que se refere ao humor, a vinculação relacionada à compreensão da maneira como esse recurso é empregado, em quais circunstâncias, com quais objetivos, especialmente relacionado ao sentido dado ao rural midiatizado. Para tanto, a explicitação de contextos em que o humor se faz presente, figurando como uma estratégia de produção de sentido.

\begin{abstract}
Ocupando um espaço de mediador, de condutor dos diferentes gêneros presentes nos programas, o apresentador utiliza-se do humor como uma estratégia também de reconhecimento e legitimação, que teriam como resultante uma maior audiência. Essas relações, tomadas pela produção dos programas como sendo de garantida eficácia, no que diz respeito a audiência são tencionadas e revelam aspectos presentes em sua constituição. (BIANCHI, 2003, p. 18).
\end{abstract}

A tentativa de se estreitar o caráter relacional entre apresentador/ouvinte é expressa em uma espécie de diálogo que o apresentador procura estabelecer com o receptor. 0 espaço opinativo do qual dispõe, interferindo diretamente na produção do programa, é investigado na medida em que contribui de maneira efetiva na construção do rural midiatizado. Para isso, além da escuta, houve a realização de entrevistas com os apresentadores, investigando de que maneira se constrói o posicionamento do apresentador enquanto mediador e condutor do programa, constituindo esse aspecto em uma estratégia produtiva (BIANCHI, 2003, p. 18).

Nesse sentido, a investigação de relações que estão presentes na produção e no próprio produto e que evidenciam a concepção de um ouvinte ao qual o programa se destina também é analisada. Relações essas que se apresentam na forma de tratamento nominal dispensado pelos apresentadores a determinados ouvintes, determinação e tratamento de ouvintes pela profissão ou localidade que habitam. Tais aspectos estão presentes e participam da estratégia produtiva do programa, via apresentador. 


\section{As articulações entre produção, produto e recepção e participação das mediações}

Um desafio que se coloca quando da condução de uma investigação que articula as distintas fases concernentes ao processo comunicacional diz respeito à maneira como determinadas opções e decisões são conduzidas. Nesse sentido, o esforço em compreender e também contemplar as possibilidades no que consideramos como etapas relacionadas à produção, à conformação de produtos midiáticos e também seus processos de recepção.

Assim, é possível considerar uma série de questões que são levantadas como passíveis de investigação em função de se estar analisando o processo comunicacional. Nessa inserção, aspectos relacionados à produção midiática, sugerindo a necessidade de se relacionar as estratégias midiáticas com os usos dos programas realizados pela recepção, a identificação e compreensão das formas em que se dão as construções simbólicas que vinculam sentido ao rural por parte dos programas em análise, além de estabelecer e compreender as relações existentes entre uma realidade rural vivida pelos ouvintes e o rural midiatizado nesses programas.

No âmbito da recepção, a investigação de como se manifestam os usos, as apropriações, as recusas da oferta midiática, a busca pela compreensão de como, da perspectiva dos receptores, se configuram as relações simbólicas entre o rural vivenciado e o rural midiatizado pelos programas radiofônicos. Além disso, a maneira como se dá o relacionamento entre o global e o local no que diz respeito à escuta, aos usos, às apropriações e às recusas da oferta midiática, especialmente relacionada aos dois programas de rádio. 0 contexto em que estão inseridos os ouvintes irá operar como uma das mediações existentes no seu consumo midiático (BIANCHI, 2003).

A partir de observações vinculadas às questões expostas sobre a produção e a oferta midiática, passa-se a refletir sobre essas relações e sua participação no relacionamento dos indivíduos participantes da recepção com a mídia. A forma como essas estratégias que figuram na produção e nos produtos midiáticos está também presente na apropriação da oferta midiática. Os mecanismos existentes nessa configuração, que pode ser representada pelo uso de táticas de recepção, e que relacionam a (re) significação do que é veiculado pela mídia.

Para a observação do relacionamento existente entre o rural vivido e midiatizado é importante, no que se refere à recepção, a investigação da presença e participação dos usos, 
dos costumes, das relações instauradas a partir do cotidiano e que fazem vinculação direta e/ou indireta com o midiático. Para tanto, a investigação dos tempos, as espacialidades em que se dão tais vínculos e de que forma se instauram não só nos usos, mas no relacionamento cotidiano com a mídia, abrangendo gostos, apropriações, aceitações, recusas, relações instauradas.

No que se relaciona à recepção destes programas, são investigados ouvintes que residem em três comunidades rurais distintas, todas localizadas na região do município de Erechim, são elas: Linha Bigolin, Povoado Coan, Linha Batistela. Essas comunidades, que sintonizam diariamente a mídia rádio, tiveram seus participantes escolhidos para a investigação em função da escuta dos programas elencados e da possibilidade de se analisar as relações simbólicas existentes no relacionamento com o rural construído e veiculado pela mídia e o rural do qual fazem parte, que experenciam em seu cotidiano. Busca-se então estabelecer a maneira como se dá esse relacionamento entre o rural vivido e midiatizado a partir das apropriações, indiferenças, rejeições que os ouvintes que participam da pesquisa fazem da oferta midiática, representada aqui pelos dois programas radiofônicos que estão sendo analisados. (BIANCHI, 2003, p. 20).

Participam desse contexto mediações configuradas pelo cotidiano, por relações interpessoais, familiares, sociais e que, situadas em um contexto de consumo midiático, adquirem uma significação que está inserida no processo comunicacional. 0 relacionamento diário com a mídia rádio e observando especialmente a relação com os programas em análise, constitui relações simbólicas entre o rural vivido e midiatizado. É nessa relação que compreende a escuta dos programas, mas também temporalidades situadas antes e depois de sua duração, que irão ocorrer as apropriações e (re) significações do que irá se constituir como manifestações, representadas através do sentido, do que seja o relacionamento entre o rural vivido e midiatizado.

Nessas relações são revelados usos cotidianos da mídia, táticas, aceitações e recusas da oferta midiática. Para a percepção e compreensão de tais manifestações é que foi de grande importância a utilização de entrevistas, buscando analisar de que maneira se dá a expressão desses aspectos, sejam vinculados ao consumo de mídia, mas também nas relações que são estabelecidas para a configuração desse relacionamento. Além disso, a importância de se executar a entrevista com inserção radiofônica como forma de se acompanhar e analisar tais apropriações no momento da audição. Sabe-se que a recepção de uma oferta midiática não acontece de maneira única e isolada no instante da escuta, consistindo-se em um mecanismo de significação que vai além do espaço da veiculação, entretanto, é neste momento em que algumas manifestações podem ser observadas em sua 
expressão inicial.

Relações que abrangem espaço/tempo, as identificações entre global/local, mediações relacionadas à família, trabalho, religião, idade, gênero, e especialmente ao ambiente rural em que estão inseridas, são importantes considerações na medida em que irão determinar, em diferentes graus, como se dará o consumo midiático. Tempo/espaço são mediações fundamentais e de certa maneira determinantes no consumo dos programas em análise. As temporalidades dos programas se relacionam e precisam, de acordo com cada ouvinte, ser adequadas às temporalidades existentes no cotidiano da recepção. De alguma maneira, há uma imposição das temporalidades do indivíduo em relação as temporalidades dos programas. Busca-se compreender então esse processo de maneira mais efetiva, tentando estabelecer as relações existentes e os respectivos sentidos gerados. (BIANCHI, 2003, p. 21).

Espaços e temporalidades que determinam a escuta estão relacionados de maneira direta ao trabalho, mas perpassados por outra mediação determinante na vida dos indivíduos pesquisados: o rural. Funcionaria como uma espécie de tempo que se sobrepõe aos demais, e que de alguma maneira estabelece as demais temporalidades, como da família, do trabalho e do consumo midiático.

O espaço rural, mediação fundamental a ser considerada nessa pesquisa, revela uma multiplicidade de aspectos que são revelados para além do comunicacional, mas que, em alguma medida, possui implicação na sua constituição. Sua especificidade, se relacionada ao urbano, reside no fato de apresentar vínculos, em diferentes campos, que diferem em muito das configurações urbanas. No aspecto sociocultural, a caracterização de relações de proximidade, perpetuação dos laços de vizinhança e parentesco, manutenção de práticas religiosas, de lazer, que passam de geração para geração. No que se refere à economia, o esforço de manter o setor agropecuário em atividade, mesmo frente às exigências e imposições cada vez maiores, vindas muitas vezes de um espaço que ultrapassa o rural.

A partir de configurações no âmbito de relações econômicas, sociais, culturais, e tendo como horizonte o lugar em que elas se dão - o rural - é que as questões pertinentes à investigação do processo comunicacional são compreendidas de maneira mais consistente. Compreende-se, assim, o meio rural como um espaço com características específicas, que fazem com que as apropriações do midiático aconteçam de maneira singular.

Essa especificidade atribuída à escuta da mídia rádio em indivíduos que vivem em comunidades rurais é evidenciada por uma série de questões que são próprias do rural. Laços sólidos de amizade, vizinhança e parentesco, que são perpetuados por um tempo que, na maioria das vezes, ultrapassa a própria duração da existência de cada indivíduo. São 
valores passados de geração a geração; a ligação estreita com a terra e vínculos estabelecidos a partir dela, relacionados ao trabalho, à subsistência, à herança que é passada de pai para filho; à religiosidade, que se revela como uma referência de conduta, de valores.

Se por um lado considera-se uma série de aspectos que caracterizam o meio rural como um espaço de características singulares e que podem ser traduzidos em uma singularidade revelada no processo comunicacional, considera-se também o fato de que o meio rural está cada vez mais inserido em uma sociedade global em que o meio urbano se revela como espaço de legitimação. 0 meio rural ocupa um espaço que tem sido marcado por muitas transformações ao longo dos últimos anos. Antes mesmo de ser atravessado pelas mudanças decorrentes dos processos de globalização, o meio rural já passava por transformações, especialmente geradas em função da propagação de um sistema de industrialização do país, iniciando nas décadas de 1940 e 1950.

0 desenvolvimento industrial, seguido da globalização, são aspectos que se apresentaram como determinantes na transformação nas condições de trabalho e de vida no meio rural. 0 campo passa a ser industrializado e urbanizado, ao mesmo tempo em que é crescente a migração de indivíduos e grupos para os diferentes centros urbanos. 0 meio rural já não representa mais um lugar isolado, marcado por características vinculadas ao atraso social, econômico, cultural, mas está cada vez mais próximo da cidade, proximidade esta que não se revela somente no espaço geográfico, mas por uma série de práticas que não se apresentam mais como sendo tipicamente urbanas. Conserva em sua constituição marcas presentes desde sua concepção, mescladas com manifestações tipicamente urbanas.

Os meios de comunicação representam um dos mecanismos que fazem com que haja a quebra de uma delimitação do que seriam características marcadas pela espacialidade do urbano e do rural. 0 atravessamento de práticas, usos, costumes entre os dois espaços é em grande parte auxiliado pela oferta midiática. Nessa pesquisa investiga-se também a participação da mídia na configuração desses atravessamentos que se estabelecem entre o rural e o urbano a partir das configurações evidenciadas no relacionamento entre rural vivido e midiatizado. (BIANCHI, 2003, p. 23).

A relação que os receptores estabelecem com um meio de comunicação diz muito não apenas sobre seus usos e fazeres, mas possibilita a observação de potencialidades e limites do próprio meio. No caso do rádio, a mobilidade proporcionada, as diferentes temporalidades que permite estabelecer e os contextos gerados pela escuta o caracterizam 
como um meio de potencialidades que são acionadas de acordo com o referencial de cada ouvinte.

O consumo radiofônico permite perceber e relacionar práticas culturais que fazem vínculo com o cotidiano, com as relações sociais, as identidades e o imaginário dos consumidores midiáticos. A observação do midiático a partir da cultura possibilita relacionar o consumo do rádio em sua forma simbólica, considerando os contextos e os processos históricos, sociais e culturais em que essa relação se dá.

As reflexões tecidas por Martín-Barbero foram importantes na medida em que coloca o popular como o lugar de onde se observar os processos de comunicação, da perspectiva de sua multiplicidade e heterogeneidade. De uma perspectiva cultural, entendendo cultura em sua relação com diferentes instâncias da vida dos indivíduos, Martín-Barbero buscará em suas manifestações os subsídios para se compreender a mediação social e comunicacional com o popular. Em suma, a busca por se investigar os processos comunicacionais não somente a partir e no nível dos meios, mas sim das mediações envolvidas.

Essa visão relacionando meios e mediações está presente neste trabalho em diferentes aspectos. No que se refere à recepção, o interesse em se investigar sim a relação dos ouvintes com o rádio, mas também esse entorno, que circunda e compõe o midiático: usos e consumos executados, mediações na escuta, recusas da oferta midiática, (re) significação das mensagens veiculadas, histórico de vida e de consumo midiático e relações de tempo e espaço. Na produção dos programas e mesmo nos produtos midiáticos, a participação de mediações profissionais, tempo-espaciais, econômicas, entre tantas outras.

\section{Considerações finais}

As referências trazidas com relação à pesquisa desenvolvida consideraram como preponderante o fato do rural se apresentar como a mediação primeira no consumo radiofônico. Essa constatação vai além de uma questão meramente instrumental, mas está relacionada ao consumo simbólico. Da mesma forma, as relações estabelecidas com o midiático dizem respeito a um universo no qual os receptores estão inseridos. 0 rural é sim essa marca principal, mas é acompanhado de perto por mediações familiares, de trabalho, amizade. 0 rádio é significado a partir dessas mediações e de alguma forma, também participa em suas constituições. A história com o rádio, o lugar que ele ocupa no cotidiano, são aspectos que revelam a importância de se considerar a série de relações que circundam 
o consumo midiático.

O funcionamento desses mecanismos produtores de sentido não se configura de maneira simples e também não são simples suas análises. É necessário estar atento, perceber os contextos em que se dá a observação, as relações que são estabelecidas, os conflitos e as contradições. Além disso, as construções de sentido vinculadas ao midiático têm suas temporalidades distintas, pois não se dão somente no momento presencial da escuta. São elaborações simbólicas que se dão no antes e no depois.

Tais percepções e reflexões só foram possíveis pela consideração da perspectiva desenvolvida por Martín-Barbero e que traz o destaque para a consideração das mediações no processo comunicacional. Nesse sentido, percebe-se no próprio avanço da prática investigativa a relevância e sentido contido nesse tipo de apropriação.

\section{Referências}

BIANCHI, Graziela Soares. Rural vivido e midiatizado - relações simbólicas e sentidos produzidos a partir da escuta dos programas radiofônicos Hora do Chimarrão e Brasil de Norte a Sul por ouvintes das comunidades rurais Linha Batistela, Povoado Coan e Linha Bigolin. 2003. Dissertação (Mestrado em Comunicação) - Programa de Pós-graduação em Ciências da Comunicação, Universidade do Vale do Rio dos Sinos, São Leopoldo, 2003.

BOURDIEU, Pierre. A distinção: crítica social do julgamento. São Paulo: EDUSP, 2007.

MARTÍN-BARBERO, Jesús. De los medios a las mediaciones. México: Gustavo Gilli, 1987.

MARTÍN-BARBERO, Jesús. Processos de comunicación y matrices de cultura: Itinerario para salir de la razón dualista. México: Gustavo Gilli, 1988.

MARTÍN-BARBERO, Jesús. De los medios a las mediaciones: comunicación, cultura y hemonía. Santafé de Bogotá: Convenio André Bello, 1998.

MARTÍN-BARBERO, Jesús. Los ejercícios del ver: hegemonía audiovidual y ficción televisiva. Barcelona: Editorial Gedisa, 1999.

MARTÍN-BARBERO, Jesús. Oficio de cartógrafo: travesías latinoamericanas de la comunicación em la cultura. Santiago do Chile: Fondo de Cultura Econômica, 2002.

MARTÍN-BARBERO, Jesús. Tecnicidades, identidades, alteridades: mudanças e opacidades da comunicação no novo século. In: MORAES, Denis de (Org). Sociedade midiatizada. Rio de Janeiro: Mauad, 2006. 


\title{
Perspectives and possibilities of approaching mediations in investigative work: issues involving rural and radio
}

\begin{abstract}
The culture, located in the work developed by Jesús MartínBarbero, occupies a prominent place to observe relations established with different means of communication. Considering this understanding, it is sought to advance in discussions about how, from the look that is mobilized from the culture, different processes of mediation can be investigated. In a more secluded way, the presentation of questions that involve the research with publics in rural communities in their relations and constructions of trajectories with the radio medium. In this sense, the presentation and reflection of the processes involved in the investigation of the perspective in which the rural one presents itself as an articulation mediation between the other mediations involved in a communicational process of radiophonic nature.
\end{abstract}

\section{Keywords}

Mediations. Radio. Rural. Listeners. Culture.

Recebido em 18/03/2018

Aceito em 28/05/2018 